\title{
Aproximaciones interpretativas al tratamiento informativo de la prensa durante la violencia política en Huancayo
}

\author{
Interpretive approaches to the informative treatment of the press during the political \\ violence in Huancayo
}

Elvis Jefferson Villanueva Basilio'

\section{Cómo citar}

Villanueva Basilio, E. J. (2021). Aproximaciones interpretativas a tratamiento informativo de la prensa durante la violencia política en Huancayo. Socialium, 5(1), 111-129. https://doi.org/10.26490/uncp.sl.2021.5.1.789

${ }^{1}$ Licenciado en Comunicación (Periodista), Grupo de Investigación Interculturalidad y Comunicación de la UNMSM, Lima, Perú. elvis.villanueva@unmsm.edu.pe Google scholar

Arbitrado por pares ciegos Recibido: 5/10/2020 Aceptado: 20/11/20

\section{RESUMEN}

Este artículo brinda algunas aproximaciones para el estudio de la prensa escrita durante la violencia política en la zona centro del Perú, especialmente en la provincia de Huancayo. El estudio se enfocó en tres sonados casos de violencia política acaecidos en 1986 y 1989 en Huancayo, los mismos que fueron comentados en el Informe de la Comisión de la Verdad y Reconciliación del Perú. Para ello, se analizó el tratamiento informativo que le dieron a esos casos los diarios locales Correo y La Voz de Huancayo. Se encontró que estos impresos ofrecieron un tratamiento informativo que se caracterizó por el sensacionalismo, politización, imprecisión informativa y el escaso ejercicio de la investigación periodística. Se concluyó, además, que en los casos estudiados, no se fomentó un espacio de discusión y una opción de tratamiento periodístico que pueda neutralizar el mensaje de terror que quería propagar Sendero Luminoso en Huancayo.

Palabras clave: violencia política; terrorismo; prensa; Correo; La Voz de Huancayo.

\section{ABSTRACT}

This article provides some approaches to study the written press during political violence in central part of Peru, specifically in the province of Huancayo. This study focused on three much talked-about cases of political violence occurred in 1986 and 1989 in Huancayo, the same ones that were commented on the Report of the Truth and Reconciliation Commission of Peru. Then, the information treatment given to these cases by the local newspapers Correo and La Voz de Huancayo was analyzed. It was found that these newspapers offered an informative treatment that was characterized by sensationalism, politicization, informative imprecision, and the scant exercise of journalistic investigation.

Keywords: press; political violence; terrorism; Correo; La Voz de Huancayo. 


\section{Introducción}

Existe la idea de que la prensa escrita atizó involuntariamente la violencia política peruana en la década de los ochenta. Oviedo (1989), por ejemplo, da entender que los periódicos capitalinos propiciaron las condiciones para que se reprodujeran mensajes de tono desolador y exagerado. Sin embargo, las estadísticas de entonces cuestionaron esta percepción. Una encuesta realizada por Apoyo en 1987, en Lima, concluyó que los medios de comunicación no necesariamente fueron conductores de la violencia (Quehacer, 1987). Al respecto, Nieto (1987) puntualizó:

No es cierto, al parecer, que la prensa diaria tenga la capacidad de crear más violencia, aun a través de los titulares más descabellados. Sin embargo, sí se puede afirmar que no está cumpliendo su papel en la formación de una conciencia pública crítica fundada en los valores de una vida democrática, pacífica y solidaria. Contra esta función actúa la reiteración de titulares e informaciones que más que constituirse en formadores de esa opinión pública crítica, le quitan la posibilidad de acceder a información fidedigna, de contextualizar los hechos, y, finalmente, de entenderlos. (p.41)

No obstante, la observación de Nieto es centralista. La prensa escrita provinciana, a diferencia de la capitalina, no ha sido analizada en toda su amplitud. En la provincia de Huancayo, por ejemplo, no se ha abordado el tratamiento informativo de la prensa escrita durante la violencia política ${ }^{1}$. Durante esa etapa, en Huancayo solo existieron dos periódicos que se encargaron de orientar la opinión pública. Estos fueron los diarios La Voz de Huancayo y Correo, cuyas noticias sobre violencia política generalmente ocuparon la sección policial.

En los primeros años del conflicto, ambos periódicos desconocían el origen del grupo armado Sendero Luminoso (SL), en consecuencia, ambas cabeceras cayeron en imprecisiones periodísticas al informar las primeras acciones violentas en Huancayo. Por ello, una de las preguntas principales a explicar sería: ¿cómo fue el tratamiento periodístico de La Voz de Huancayo y Correo a la hora de informar sobre sucesos de violencia política?

Por la brevedad del espacio hemos circunscrito este análisis a tres hechos de violencia política cuyos protagonistas fueron Sendero Luminoso y el batallón antisubversivo Inclán.

\footnotetext{
${ }^{1}$ Excepto el breve estudio sobre la prensa regional del centro, en el capítulo tres del Tomo III del Informe de la CVR, y el panel Periodistas y hechos de violencia política y terrorista en Junín realizado el 2019, no hemos encontrado otros antecedentes que hayan abordado el tema de la prensa huancaína durante la violencia política.
} 


\section{Violencia política y medios de comunicación}

Durante la etapa de la violencia política en el Perú (1980-2000), algunos medios explotaron el valor comercial de las informaciones. Sobre todo, si estas noticias tuvieron que ver con las acciones de los grupos terroristas. En el cenit de las migraciones provincianas a las ciudades, este tipo de prensa encontró en las masas al lector dispuesto a consumir los estruendosos y sangrientos contenidos.

Las primeras informaciones de ataques subversivos fueron tomadas por los diarios capitalinos como simples actos delincuenciales. La mayoría los ubicaba en la sección policial. La crónica roja, los obituarios en primera plana y las fotografías explícitas de los asesinatos, fueron el alimento diario de los periódicos que desconocían las verdaderas intenciones ideológicas de SL. Peralta (2000) comenta que por entonces “(...) el sensacionalismo fue el hilo conductor de este tipo de información en la prensa" (p. 9). Una manifestación de ello fue el incremento de tiraje del diario Ojo:

En los primeros años de esta década, el crecimiento de la violencia fue paralelo al que tuvo el número y tiraje de los diarios, que alcanzó cifras récord en los dos primeros años del gobierno del presidente Alan García. En 1987, por ejemplo, Ojo llegó a tirar 500,000 ejemplares diarios a lo largo de una semana. (Gonzales, 1992, p. 14)

Otro periódico que agrandó su tiraje fue El Diario, cuyo contenido prosubversivo no impidió superar la venta de más de 25000 ejemplares diarios. De este medio se recuerda la famosa Entrevista del Siglo que Abimael Guzmán concedió en 1988 desde la clandestinidad (Strong, 1992). Sin embargo, debemos tener en cuenta que el sensacionalismo fue alentado en parte por sucesos acontecidos en Uchuraccay, Ayacucho, donde murieron ocho periodistas que habían decidido emprender una investigación periodística in situ. A partir de esta tragedia, el periodismo de investigación fue relegado por el sensacionalismo y la mera reproducción de comunicados militares. Sin libertad de expresión, ni derecho a la información, muchos medios y periodistas se sintieron desamparados en sus provincias y la calidad periodística se vio afectada.

¿Pero cuál es la relación entre los medios de comunicación y la violencia? Se entiende que el terrorismo es una forma de violencia política por el "uso de una fuerza, abierta u oculta, con el fin de obtener de un individuo o de un grupo, algo que no quiere consentir libremente" (Domenach, 1981, p.36). Se sabe también que el terrorismo no es un fenómeno nuevo. Los revolucionarios rusos de 1870 fueron los primeros en usar el terrorismo como medio de propaganda. Las víctimas se escogían en función de la resonancia que su muerte podía despertar en la opinión pública. Históricamente, se podría decir que el terrorismo y los medios de comunicación guardan una relación estrecha, pues el primero necesita del segundo para hacer sentir su presencia. 
¿Cómo puede hacerse visible un grupo terrorista? Para Thomas Laqueur, que es citado por Febres (2011), "el éxito de una operación terrorista, casi siempre, depende de la importancia de la publicidad que obtiene" (p.62). Por ello se entiende la necesidad de algunos grupos subversivos de trasladarse del campo a la ciudad. Laqueur agrega que:

(...) los terroristas e informadores parten de la misma hipótesis: tienen poder los nombres que tienen grandes titulares. Podemos decir que los terroristas a través de ensayos inmediatos sucesivos han terminado por aprender a montar la coreografía para un suceso periodístico ideal (...) bien puede decirse que el botín principal del terrorismo es la audiencia, y el rendimiento único que busca es la modificación de actitudes sociales y públicas, es decir un rendimiento comunicativo (Febres, 2011, p. 62).

La importancia que le dé la prensa a los actos terroristas dependerá de ciertos factores, según (Oviedo, 1989; Peralta, 2000; Acevedo, 2002): 1) la línea editorial del medio, si es conservadora, radical o ecléctica; 2 ) la relevancia fotográfica, cuyo mensaje tiene una poderosa carga semiótica; y 3) la subjetividad periodística, que suele depender de la observación del reportero, el texto no siempre será el esperado o el que debería de darse, los reporteros conceden mayor importancia a algunos aspectos que nosotros no.

Ante estas circunstancias, muchos periodistas se preguntaron cómo poder informar en tiempos de violencia política. Peralta (2000) recurre a Álvarez quien, en su estudio titulado Shining Press and Militar Path, se hizo las mismas preguntas: ¿cómo cubrir las acciones armadas de SL sin promoverlas? y ¿cómo cubrir las acciones militares sin provocar una disrupción del sistema democrático, pero defendiendo los derechos humanos? Una posible respuesta podría ser la que nos da Febres (2011):

(...) los atentados [terroristas] que ellos realizan son un instrumento de divulgación a nivel general, así que la publicación de ellos en la prensa es una manera de ser publicitados por los periodistas. Los terroristas y guerrilleros urbanos llegan al dominio público por medio de los diarios, así que un periodista debe dosificar las informaciones acerca de ellos. La tónica es restringir sin ocultar. (p. 45)

Hubo algunos medios que no quisieron ser difusores indirectos de los grupos subversivos, pero esto los obligaba a elegir entre un nuevo enfoque periodístico (una opción podría haber sido intensificar el periodismo de investigación con reporteros nativos, pero esto se complicó a raíz del caso Uchuraccay y la supresión de libertades) o perder la demanda de lectores. La mayoría prefirió sobrevivir en el mercado. 
Por otro lado, se ha dicho que la prensa tuvo un papel importante en la difusión de las acciones terroristas. En contraposición a esta idea la Organización de las Naciones Unidas para la Educación, la Ciencia y la Cultura (Unesco), a través de un estudio elaborado por James Halloran sobre la violencia en la televisión (lo cual es válido también para la radio y la prensa), concluye que no es la violencia reproducida en TV la causante total que desencadena actos agresivos en las personas, sino que existen otras experiencias que van coadyuvando a que esta conducta estalle (Halloran, 1981), por ejemplo, los centros educativos, la familia, etc. Halloran (1981) afirma luego que, más que incitar a la violencia, los medios de comunicación tratan de mantener el statu quo de la sociedad - sea violenta o no -, y agrega que:

[los medios] informan, sacan los hechos a la luz, crean una conciencia, redefinen los límites de lo aceptable y lo no aceptable y estructuran las percepciones de la índole y la magnitud de la violencia. Al hacer esto agrupan a la gente en oposición al desorden, refuerzan la creencia en valores comunes, facilitan la imposición de sanciones y refuerzan el control social. (p.153)

Cercano a las ideas de Halloran fue Álvarez, citado en Peralta (2000), quien dice que "la influencia de la comunicación [en los medios] no radica en su poder de persuasión inmediato, sino en la capacidad de organizarle al público en un largo plazo los temas sobre los cuales debe pensar y la forma de reaccionar a los mismos" (p.21).

De acuerdo a las ideas de Halloran y Álvarez, advertimos que en los años ochenta los medios respaldaron, en parte, un statu quo de zozobra y terror impuesto, a golpe de atentados, por SL.

Naturalmente, tampoco responsabilizamos a los medios de comunicación como colaboradores directos de la violencia, ni como espacios donde se incubaron ideas a favor de la revolución senderista. Podríamos decir que los medios solo reflejaron una realidad violenta a partir de una sociedad donde las estructuras sociales estaban rotas y los gobiernos de turno perdían diariamente presencia política en el país.

\section{La prensa escrita durante la violencia política en Huancayo}

Huancayo fue, entre varias ciudades del centro, la más acosada por el terrorismo, al respecto el Informe Final de la Comisión de la Verdad y Reconciliación (CVR) señaló: “Evidentemente, cualquier acción en esta última [Huancayo] tenía mayor repercusión en la sociedad regional y en la opinión pública nacional y generaba mayor temor. Al igual que la ciudad de Lima, Huancayo fue una caja de resonancia privilegiada para las acciones subversivas (...)" (CVR, 2003a, p. 201). Para el sociólogo Nelson Manrique, la importancia de Huancayo para los senderistas desde un periodo tan temprano 
fueron dos: 1) era un territorio estratégico (nudo de caminos, alta densidad demográfica y comercial, cercanía a núcleos mineros como la empresa Centromin; y 2) la hidroeléctrica del Mantaro (las redes energéticas atraviesan Huancayo para llegar a Lima, el desabastecimiento eléctrico causa zozobra y afecta la economía nacional) (Manrique, 1999).

A mediados de los ochenta, los senderistas ya se habían infiltrado en algunas universidades del país. En Huancayo, la Universidad Nacional del Centro fue tomada por alumnos y profesores que creían que no solo había que adoctrinar a las clases estudiantiles, sino también a los campesinos de las zonas alto andinas, donde, a falta del Estado, SL encontró un espacio para instalar sus bases de apoyo (Gorriti, 2017), mientras que en la ciudad los ataques a las instituciones públicas y privadas complementaban el plan.

La primera acción subversiva en la ciudad de Huancayo fue el lanzamiento de cargas explosivas contra el puesto policial y la municipalidad distrital de Chilca, el 1 de setiembre de 1980. El 22 del mismo mes se atentó contra la Corte Superior de Justicia de Junín, el juzgado de tierras y la municipalidad de Chilca; el 11 de setiembre la oficina del Plan Meris - ubicada en el distrito de El Tambo - fue dinamitada, y dos días después los subversivos derribaron una torre de alta tensión de la línea de interconexión de la central hidroeléctrica del Mantaro, en el distrito de Chambará, Concepción. Al día siguiente, en el distrito de El Tambo, dinamitaron el depósito de la Empresa Nacional de Comercialización de Insumos (ENCl), y, por último, el 16 del mismo mes, los militantes del PCP-SL atacaron con cargas de dinamita el local de Acción Popular, en la ciudad de Huancayo. (CVR, 2003a, pp. 180-181)

La destrucción planificada de la infraestructura urbana fue para los senderistas un vehículo de propaganda ${ }^{2}$. Las famosas voladuras de torres de alta tensión y los apagones en la capital, fueron las formas de hacer sentir su presencia, además de las irrupciones en los centros mineros y sindicatos para tomar explosivos y amenazar a sus dirigentes. Sin embargo, según la CVR, entre los años de 1980 y 1985 , tiempo en que la presencia de SL en los diarios de Huancayo era aún intermitente, el registro de víctimas no fue numeroso. Un breve repaso a las portadas de los periódicos de Huancayo publicados entre 1980 y 1982, nos revela que los editores no tenían una información precisa sobre

\footnotetext{
2 Otro modo de propaganda fueron los grafitis, al respecto Peralta (2000) dice: "A través de los grafitis, cuya ingenuidad icónica, espontaneidad y autenticidad según analizan Brondi y Zapata, 'el discurso senderista se había proveído de un auténtico código, escrito y visual, que le permitió patrocinar sus propios canales de emisión'" (p.19).
} 
SL y, más bien, se limitaban a reproducir los atentados senderistas en las zonas periféricas de Ayacucho.

Será a partir del incremento de los asesinatos y atentados a las instituciones públicas cuando Correo y La Voz de Huancayo tuercen la mirada hacia el grupo terrorista más sanguinario de la historia del Perú. Las páginas de ambos diarios contienen la visión que se tuvo por entonces sobre los actos terroristas y los cambios políticos y sociales. ¿Cómo observaron estos medios la época del terror?, ¿fue esta mirada "objetiva" ?, ¿sabían los periodistas locales a lo que se enfrentaban?

El diario Correo, fundado el 23 de noviembre de 1962 y auspiciado por el magnate pesquero Luis Banchero Rossi, fue uno de los pocos diarios que descentralizó la información. Con varias filiales conectadas en el norte, centro y sur, Correo de Huancayo encontró en el público provinciano un espacio fértil, pues el viejo estilo periodístico de otros impresos locales no cautivaba al lector tanto como el estilo sensacional de Correo (Osorio y Cisneros, 1967; Rojas, 1974).

Durante la década del ochenta - etapa en la que el diario cambió de línea editorial y de propietarios -, Correo supo adherirse a la carrera informativa de las acciones terroristas. Durante ese tiempo siete periodistas alternaron los mandos del tabloide: Guillermo Blanco, jefe de redacción; Teófilo Caso Oré, director; Carlos Ordoñez Berrospi, jefe de redacción; Rodolfo Orozco Miranda, director; Nilo Calero Pérez, director, y Luis Pareja Santillán, director. A este grupo le secundaron un equipo de periodistas y fotógrafos que trabajaban para exclusividad de la Empresa Periodística Nacional, dueña de las filiales de Correo en provincias. Esta red permitió una continua retroalimentación de noticias entre las regiones y Lima.

Correo ha tenido un protagonismo interesante en Huancayo, a pesar de los choques con la subversión. Sin embargo, no fue el único medio afectado, recordemos cómo se hizo cotidiano el secuestro de las emisoras locales ${ }^{3}$ por los terroristas y las fuerzas del orden en Huancayo. El testimonio de la presidenta de la Asociación de Locutores del Centro del Perú Rosana Alarcón es revelador:

Los comunicadores nos sentíamos amenazados por ambas fuerzas. Los grupos alzados en armas nos amenazaban y querían copar los medios de comunicación con un interés desleal hacia la población de fomentar su ideología, pero supimos defendernos. Por su parte, el Estado también quiso copar los medios, comprándolos, por eso no se revelaban muchos

\footnotetext{
3 Según un cuadro cronológico sobre la violencia política en el Perú desde 1980 a 1988, fueron Radio Universal y Radio Andina las más acosadas por las huestes terroristas en la zona centro (DESCO, 1989).
} 
hechos de violencia que cometían los militares de ese entonces. (CVR Región Centro, 2003, p.34)

En los primeros años de la década del terror, Correo catalogaba a los senderistas como "un grupo extremista", "unos radicales" o unos "vándalos extranjeros". Esta imprecisión sobre la naturaleza de los subversivos no solo fue exclusiva de la prensa provinciana, sino también de los diarios capitalinos que - respaldados por los comunicados oficiales del gobierno de Fernando Belaunde - catalogaban a SL como "4 gatos que están cometiendo actos de terrorismo" (DESCO, 1989, p.565). No está demás decir que las voladuras de torres eléctricas y los dinamitazos en los centros públicos, fueron incluidos y explotados en las páginas policiales de Correo.

Fue en abril de 1983 cuando Correo tomó una posición frontal contra los terroristas que atacaron la redacción del periódico. La nota del siguiente día del atentado dice así:

Las continuas amenazas que CORREO ha venido recibiendo durante los últimos meses, ayer en la madrugada fueron efectivizadas con un atentado que ha dañado la fachada de nuestro local del jirón Cuzco, en un presumible intento de acallar nuestra firme posición de defensa de la Democracia y las libertades ciudadanas. (...) Y, justamente, este hecho nos lleva a conjeturar que el terrorismo que alientan grupos extremistas ha llegado a nuestra pacífica población con su secuela de intranquilidad y zozobra, de daños materiales, de muerte y destrucción (...) CORREO rechaza hoy estos intentos criminales, vengan de donde vengan, en resguardo de la integridad de sus instituciones y de la población misma. (Correo, 1983, p.1)

A partir de este acontecimiento Correo empieza a preocuparse por las motivaciones de los ataques senderistas.

Por otro lado, existió una poderosa dificultad para la libertad de información. A diferencia de los periodistas y senderólogos limeños que no estuvieron muy expuestos a las represalias de los terroristas y las FF.AA., los periodistas de provincia (y, más aún, de las provincias invadidas por SL) sí tuvieron que afrontar este problema. Dice Cueto (2009) al respecto:

Los medios locales, durante estos años, fueron presionados por ambos contendientes en mayor o en menor grado, motivando así limitaciones a la libertad de expresión, siendo evidente que tanto los senderistas como las fuerzas del orden conocían perfectamente quiénes eran periodistas, dónde vivían además de informaciones referidas a la familia. (p.43)

Empero, Correo se enfrascó en una lucha editorial contra la ideología de SL, condenó y repudió cada acto de su "guerra de guerrillas" y se alineó al oficialismo. Por entonces no se hablaba en sus páginas de excesos militares y se informaba ciegamente siguiendo los comunicados de Estado. Años después 
se revelaría la existencia del batallón antisubversivo Inclán que se hacía pasar por emerretistas para cometer desapariciones de personas sospechosas de terrorismo (CVR, 2003b, p. 377).

En el caso del diario La Voz de Huancayo, esta tuvo una larga tradición periodística. Fue uno de los primeros que se editaron en la provincia de Huancayo. Su aparición data del 15 de diciembre de 1912. Los dueños del diario fueron los hermanos Delgado De la Flor.

A inicios de los sesenta, con el cambio de gobiernos y la irrupción del diario Correo en la región centro, La Voz de Huancayo afrontó su primer declive empresarial. La dirección del medio fue asumida por la familia Pardo Heeren y absorbida por la cadena de diarios DASA (Diarios Asociados S.A). Hasta fines de esa década, La Voz de Huancayo se mantuvo bajo la administración de los Heeren y la dirección periodística al mando de César Arauco Aliaga. En 1978 obtuvo la propiedad de DASA el exdirector del diario La Crónica de Lima, Pedro Morales Blondet (Gargurevich, 2005). Bajo la propiedad de Morales Blondet, el diario La Voz de Huancayo fue editado por un equipo de periodistas anónimos en su mayoría. Solo en algunas columnas de opinión y notas informativas aparecen créditos periodísticos. La importancia de La Voz de Huancayo durante el conflicto armado interno ha sido descuidada.

Durante la década de los ochenta el diario cubrió la mayoría de los sucesos terroristas, aunque no con el mismo despliegue que el diario Correo. La Voz de Huancayo venía siendo un diario que subsistía por el apoyo económico ajeno a las ventas y la publicidad en sus páginas. A diferencia de Correo, que le había arrebatado gran parte de sus lectores, las ediciones de La Voz de Huancayo eran rudimentarias e ilegibles. Por ello las primeras noticias sobre terrorismo que aparecieron en sus páginas no fueron justamente los que acaecían en la región Junín, sino en Ayacucho.

La línea editorial de La Voz de Huancayo estaba subyugada a los intereses de Morales Blondet, personaje conocido por sus coqueteos con familias poderosas como los Prado, fundadores de La Crónica y dueños de haciendas e industrias peruanas. La tónica periodística de La Voz de Huancayo fue ecléctica frente a la violencia política, sobre todo, la violencia proveniente de las Fuerzas Armadas. Cuando no había noticias sobre la subversión, el diario colocaba refritos y notas de la capital; sus notas fuertes, en cambio, eran aquellas que dejaban una sensación de terror y desamparo en los ojos de los lectores.

\section{Métodos}

Como esta investigación es una aproximación interpretativa a los estudios sobre el tratamiento periodístico de la prensa en contextos de violencia política, se puede señalar que es de tipo exploratoria porque el objeto de estudio aún no ha sido investigado en su amplitud (Hernández et al., 2006). El estudio, asimismo, ha seguido el método inductivo. 
Las técnicas de recolección de datos fueron el análisis documental y el análisis de contenido, las cuales tuvieron como instrumento una ficha de análisis que se aplicó, siguiendo los procedimientos sugeridos por Ñaupas et al. (2013), a las unidades de estudio.

La muestra ha sido constituida por cinco notas informativas de los diarios Correo y La Voz de Huancayo del 5 de julio de 1986 ( 2 notas), del 13 de abril de 1989 ( 2 notas) y 6 de noviembre de 1989 (1 nota). Además, se consultó algunas notas informativas posteriores a nuestra muestra para hacer el seguimiento de la noticia en los dos periódicos.

Del mismo modo, la selección de estas cinco notas responde a la importancia de los eventos que abordaron. Las notas del 5 de julio de 1986 responden a la noticia del asesinato por parte de senderistas a un militante y trabajador aprista de la Universidad Nacional del Centro del Perú. Las notas del 13 de abril de 1989 abarcan la noticia de la matanza de 12 autoridades de la comunidad de Chongos Alto por parte de SL. Y, finalmente, la nota del 6 de noviembre de 1989 corresponde al asesinato de ocho pobladores por parte del batallón Inclán. Estos dos últimos, por su gran impacto, fueron investigados por la CVR.

\section{Tabla 1}

Muestra y periodo de estudio

\begin{tabular}{lcc}
\hline \multicolumn{1}{c}{ Nota informativa } & Medio & Fecha \\
\hline iHuancayo repudia a caínes! & Correo & $05 / 07 / 1986$ \\
Asesinan empleado de UNCP & La Voz de Huancayo & $05 / 07 / 1986$ \\
Matan más de 15 en zona altoandina & Correo & $13 / 05 / 1989$ \\
Asesinan a 12 autoridades en Chongos Alto & La Voz de Huancayo & $13 / 05 / 1989$ \\
Matanza en Pucará & La Voz de Huancayo & $06 / 11 / 1989$ \\
\hline
\end{tabular}

\section{Resultado}

\section{Asesinato de Abel Bonet}

El asesinato de autoridades políticas y universitarias se hizo común durante la luctuosa campaña de SL. El amedrentamiento y los "juicios populares" contra las autoridades elegidas en democracia fueron formas de "restituir" el poder del pueblo bajo la mirada de los jefes senderistas. La muerte del dirigente aprista Abel Bonet fue un ejemplo de ello. Bonet, quien en 1961 atentó con una pedrada contra el presidente Manuel Odría en plena campaña electoral por la sierra, fue conocido por promover los famosos "grupos de choque" apristas en la Universidad Nacional del Centro, junto al rector Nilo Arroba Niño (Galván, 2014, p.24). Los asesinatos selectivos contra las fuerzas rivales 
políticas de entonces (apristas, izquierdistas, democristianos, acciopopulistas, etc.) tuvo una fuerte repercusión en Huancayo. El testimonio recogido por la CVR al señor Ricardo Bohórquez recuerda la muerte de Bonet y otros políticos:

Es necesario mencionar por ejemplo que los crímenes selectivos (...) se inician un veinticuatro (24) de julio con la muerte de don Saúl Muñoz Menacho, un distinguido alcalde de Izquierda Unida y de cuyo...de cuyo municipio yo fui regidor. Continúan estos crímenes selectivos que ensangrentaron esta parte del territorio nacional con el asesinato de un distinguido dirigente del partido aprista, don Abel Bonnet García, que se desempeñaba como funcionario y como administrador general de la universidad, y precisamente él es víctima de un atentado mortal que le quita la vida en las inmediaciones de su universidad, del local central de la Universidad Nacional del Centro. (CVR, 2002)

La muerte de Bonet acaecida el 4 de julio de 1986 a manos de senderistas fue noticiada por Correo y La Voz de Huancayo (Figura 1), cada uno desde un punto de vista diferente.

\section{Figura 1}

Portadas de Correo y La Voz de Huancayo sobre el asesinato de Abel Bonet

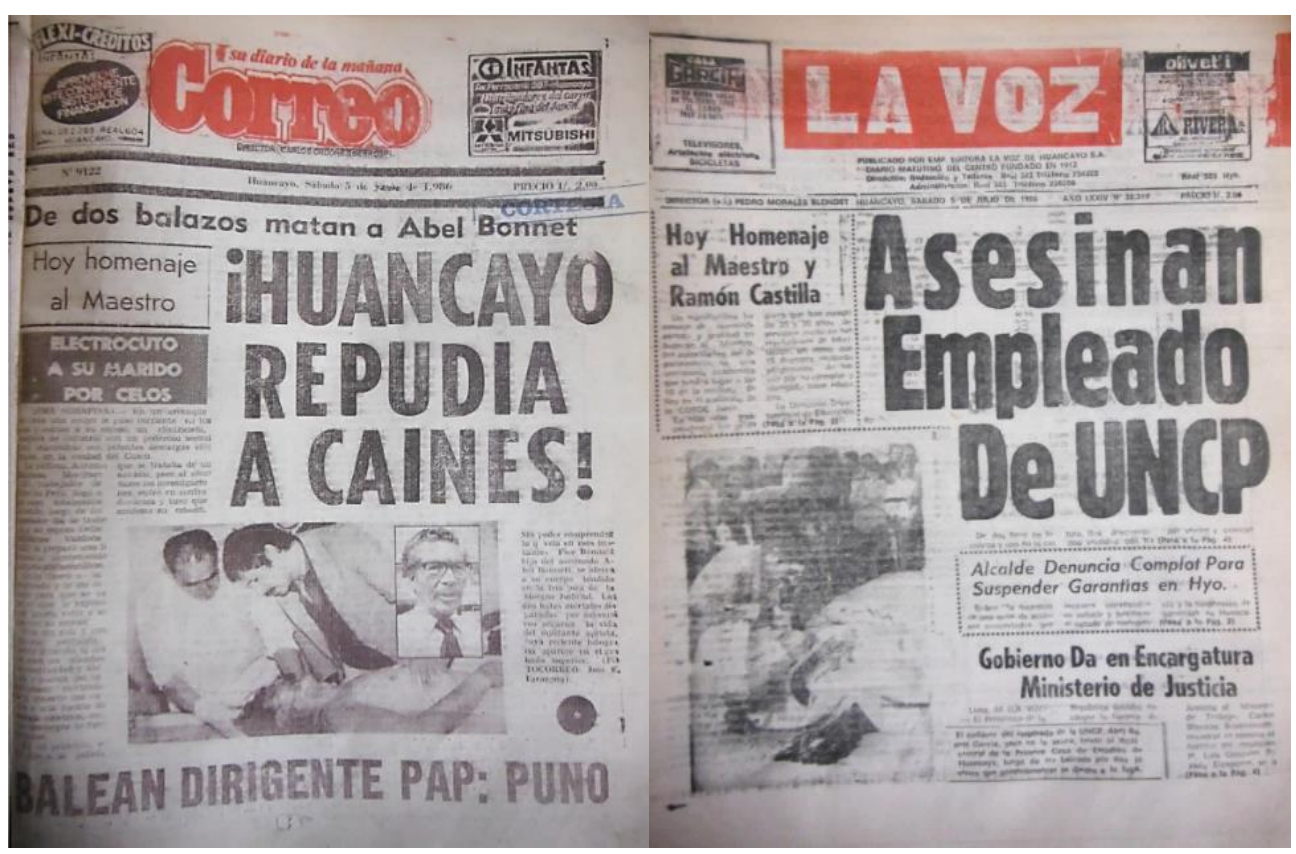

Nota. Tomado de Correo y La Voz de Huancayo del 5 de julio de 1986.

Mientras que Correo generalizaba en su portada su rechazo contra los autores del crimen, La Voz de Huancayo presentó un titular neutral. Correo enfatizó en la nota por tratarse de Abel Bonet, un militante aprista, ofreciéndole tres páginas de cobertura. 
Para La Voz de Huancayo, en cambio, la importancia de Bonet se justificaba por su cargo laboral, "un empleado de la UNCP”, y le dedicó solo media página. ¿Por qué esta diferencia? Para entonces Correo había sufrido el atentado de los subversivos y la guerra contra SL estaba declarada. Además, los altos directivos editoriales de Correo estaban ligados a la ideología aprista. De modo que la muerte de un reconocido militante, como lo fue Bonet García, significaba una afrenta contra el gobierno de turno y las simpatías del diario. En la página 7 de la edición mostrada, se puede leer una columna escrita por Carlos Hidalgo Pallete, secretario aprista en Huancayo y exdirector de Correo durante la década del sesenta, quien pide una investigación exhaustiva del caso.

Por otro lado, para La Voz de Huancayo este suceso no pasó de ser un hecho luctuoso contra un funcionario público que no estaba ligado a la ideología del diario. Recordemos que la Voz de Huancayo pertenecía a un conglomerado de diarios de propiedad de los herederos de Morales Blondet, quienes estuvieron asociados a la rancia oligarquía peruana. En consecuencia, se colige que a la hora de informar influían las preferencias políticas e ideológicas en cada diario.

¿Cómo aprovechó SL la difusión de este crimen? Como dijimos, la postura de Correo fue clara: combatir todo acto proveniente de SL. En la noticia sobre Abel Bonet, Correo se adelantó, antes de una investigación judicial, a calificar a los asesinos como subversivos y senderistas. Algunas líneas dicen así: "Las dos balas mortales disparadas por los subversivos", "Los terroristas cubrieron su rostro con pasamontañas", "Se halló un letrero con la inscripción: por cada Senderista muerto en Lurigancho, morirán 10 apristas" (las cursivas son nuestras). Este dato fue favorable para SL, ya que se reprodujo un mensaje que, sin vincularlo a un asesinato, no hubiera llegado a su objetivo, ni hubiera sido relevante. Correo, indirectamente, difundió el mensaje de su enemigo.

Otra es la situación de La Voz de Huancayo cuyos redactores fueron precavidos al presentar una filiación senderista de los asesinos. Estos son algunas frases a propósito de la muerte de Abel Bonet: "Los audaces criminales se levantaron y empezaron a caminar y apenas cruzaron con la víctima le dispararon", "Testigos del crimen vieron una cartulina con la hoz y el martillo con la siguiente inscripción: Por cada muerto en el Frontón morirán 10 apristas (la cursiva es nuestra). En ninguna de estas frases se hizo alusión directa a SL, y es posible que el informe periodístico que esperaban los subversivos al día siguiente no satisfizo sus expectativas, pues recordemos que la hoz y el martillo como símbolos eran usados también por el Partido Comunista Peruano, del cual Sendero deslindó y 
rechazó su semejanza ${ }^{4}$. SL en esa oportunidad perdió un espacio de propaganda directa, ya que el diario no señaló a los senderistas como victimarios de Abel Bonet, como sí lo hizo Correo.

\section{Muerte de 12 autoridades}

Fue un 12 de abril de 1989, cuando 40 senderistas irrumpieron violentamente en la plaza principal de Chongos Alto y, lista en mano, empezaron a sacar de sus casas a 12 autoridades del pueblo. La matanza fue breve y atroz. Según la CVR el móvil que alentó a los terroristas a ejecutar esta masacre fue:

(...) el conflicto que existía entre Chongos Alto y Huasicancha. Ambas comunidades se disputaban la propiedad de unas 10 mil hectáreas de tierras desde mucho tiempo atrás, por lo que algunos sectores - en ausencia de mecanismos eficaces de resolución de conflictos desde el Estado - buscaron resolver el litigio acudiendo a los mandos de la columna senderista, que buscaban presentar sus actos como la mera ejecución de la voluntad de la gente. Diversos testimonios recogidos por la CVR señalan que, independientemente de las reuniones de las autoridades, la matanza fue instigada por algunos comuneros de Huasicancha, que acusaron a los pobladores de Chicche, Llamapsillón y Chongos Alto de querer ponerse en contacto con las fuerzas del orden (CVR, 2003b, p.315).

Es necesario mencionar que SL trató de sabotear las organizaciones campesinas como las Sociedades Agrarias de Interés Social (SAIS) - en Junín la SAIS Cahuide - impulsadas por el gobierno de Juan Velasco Alvarado. Para SL estas empresas representaban un orden social "caduco" (CVR, 2003b) y, por lo tanto, fue indispensable destruirlas. Sin embargo, su ideal no solo fue destruir esas estructuras (asesinar dirigentes y liquidar el ganado), sino también generar un clima de impotencia y desesperanza en la población huérfana del Estado. De esta forma SL creyó movilizarlos hacia una sola opción: la lucha armada. Manrique (1999) menciona que "fue la tenencia de tierras pertenecientes a la antigua SAIS Cahuide lo que provocó el enfrentamiento de las comunidades" (p. 205). Lo que habría desembocado en el asesinato de las 12 autoridades de Chongos Alto. Veamos cómo fueron las portadas de los dos diarios huancaínos (Figura 2):

\footnotetext{
4 Para Sendero Luminoso el verdadero Partido Comunista fue el que un grupo disidente había formado en Ayacucho, con algunas variantes en el título, como Partido Comunista del Perú PCP-SL.
} 


\section{Figura 2}

Portadas de Correo y La Voz de Huancayo sobre la masacre de 12 autoridades

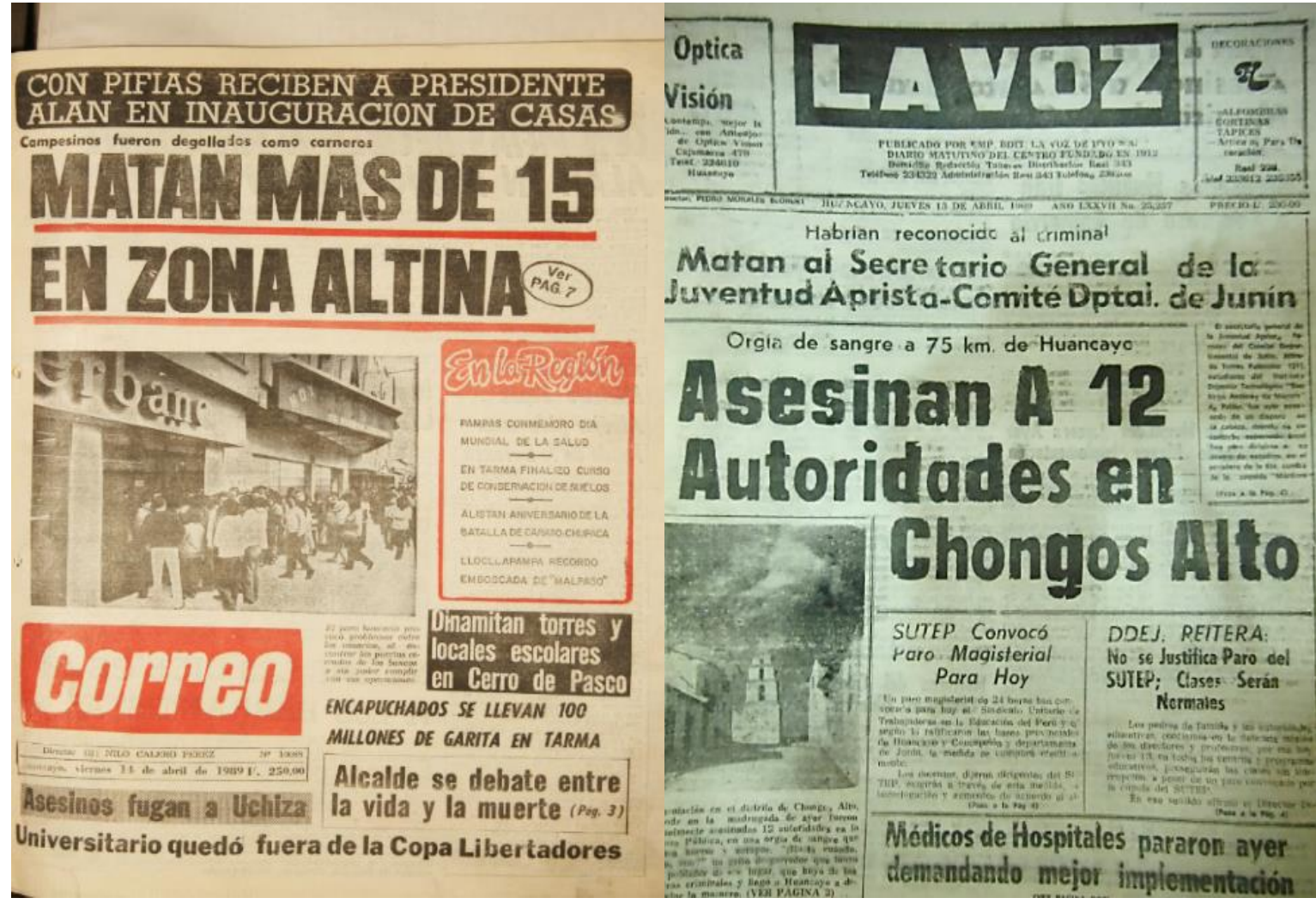

Nota. Tomada de Correo y La Voz de Huancayo del 13 de abril de 1989.

El desarrollo de esta noticia en Correo aglomeró términos como "sediciosos" e "incursión subversiva" y dejó entrever, sin confirmar, que el asesinato de las 12 autoridades fue autoría de SL. Asimismo, en la edición del día siguiente, 14 de abril, se reprodujo la explicación de un comunero sobre el funesto hecho en Chongos Alto: "Sobre este caso, un testigo indicó que el ataque se produjo después que los comuneros el 17 de marzo trajeron a Huancayo como presuntos subversivos a Orías Maraví, Lube Vivas y Gilberto Rodríguez" (Correo, 1989, p.7). Precisamente esta acusación fue parte de las acciones antisubversivas de las comunidades campesinas, en este caso, del teniente gobernador de Chongos Altos, Genaro Chanco, quien impulsó una frontal lucha contra SL.

Esto habría originado la venganza de los terroristas contra el gobernador y las otras 11 autoridades. Para SL consumar esta masacre fue, a todas luces, una oportunidad para difundir su mensaje contra los gobiernos locales, los representantes de las sociedades agrarias y los "latifundistas hambreadores".

Por otra parte, una característica común que presentaron los dos diarios al momento de cubrir hechos de violencia política fue la adopción de un lenguaje contraproducente. Según Febres (2011): 
Otro abuso grave por parte de los medios informativos ha sido adoptar el propio vocabulario, razonamientos y mitos terroristas, (...), cuando la prensa utiliza sin siquiera entrecomillar, las expresiones terroristas para sus asesinatos, "ejecución", "actos revolucionarios", "justicia revolucionaria", "castigo revolucionario por crímenes contra el pueblo", etc. se convierten de hecho en instrumentos y portavoces de la propaganda terroristas. Implícitamente están respaldando las propias justificaciones de los terroristas y guerrilleros. (p.53)

En efecto, Correo también adoptó ese vicio. En la portada de la matanza de las 12 autoridades (Figura 2), por ejemplo, hizo uso de un par de frases sugestivas: "fueron degollados como carneros" y "orgía de sangre" para referirse a la forma en que fenecieron las víctimas. Apegado al sensacionalismo, Correo no se percataba de colaborar con un statuo quo imaginado por $\mathrm{SL}^{5}$, es decir, una sociedad desprotegida y huérfana del derecho a la vida, una ciudad tomada por los terroristas. La otra frase "orgía de sangre" no hace más que robustecer la imagen despiadada y letal del grupo subversivo.

Por otro lado, el diario La Voz de Huancayo utilizó también los términos "orgía de sangre" como cabeza de titular y dramatizó los hechos sin deslizar un posible autor del crimen. No obstante, este medio, a pesar de adoptar las palabras "subversivo" o "terrorista" a finales de la década, pocas veces señalaba a SL como autor de los atentados. Prefirió, más bien, reproducir comunicados oficiales de Lima o tomar como fuente a un "informante secreto" como en la noticia del 13 de abril. Con estas limitaciones periodísticas ( $L a$ Voz de Huancayo no tenía una amplia plana de corresponsales), este diario no pudo ser una eficaz caja de resonancia de la propaganda de SL.

\section{Matanza en Pucará}

La CVR ha sindicado al batallón antisubversivo Inclán como autor de la matanza de 8 pobladores del distrito de Pucará, en Huancayo, acaecido el 4 de noviembre de 1989. Un informante de los militares apodado Rompe fue quien señaló a las víctimas como miembros de SL, incluso acompañó al escuadrón militar a las respectivas viviendas de los "senderistas". La CVR concluyó al respecto:

(...) miembros del Ejército pertenecientes a inteligencia del cuartel 9 de Diciembre y al batallón antisubversivo Inclán, ingresaron la madrugada del 4 de noviembre de 1989 en el distrito de Pucará con el propósito de ejecutar extrajudicialmente a (...) Paulino Cabezas Cóndor, Raúl Cabezas Cueva, Leoncio Orihuela Medrano, Isauro Valdez Rojas, Nilo Castillón Laveriano, Máximo Pérez Ureta, Gladis Poma Vila y Madeline Poma Vila (...) Luego de cometer

\footnotetext{
${ }^{5}$ Sobre los medios de comunicación y su papel en la formación de un statu quo, véase en la Referencia a Halloran (1981).
} 
los asesinatos, los militares de la segunda patrulla hicieron detonar cargas explosivas en la plaza de armas de Pucará y realizaron pintas alusivas al MRTA con el objetivo de atribuir los asesinatos al referido grupo subversivo (CVR, 2003b, pp. 389-390).

Según Manrique (1999) el procedimiento del asesinato era "una táctica seguida por las FF.AA. para agudizar los enfrentamientos entre los senderistas y emerretistas, tratando de mostrar la masacre de campesinos prosenderistas como una acción cometida por una columna del MRTA" (p.211).

A este tipo de violencia política se le conoció como desapariciones forzadas, y en Huancayo estuvieron a cargo del Frente Mantaro, el cual, se dice, estuvo involucrado en la desaparición de estudiantes de la UNCP (Huacasi, 2008, pp. 5-9). Para 1989 la situación de las desapariciones se había agudizado. Las fuerzas del orden no daban mayores datos a los familiares de los desaparecidos y los medios de comunicación escritos no hacían eco de estos casos. Veamos cómo La Voz de Huancayo informó sobre la matanza de Pucará:

\section{Figura 3}

\section{Portada de La Voz de Huancayo sobre la matanza de Pucará}

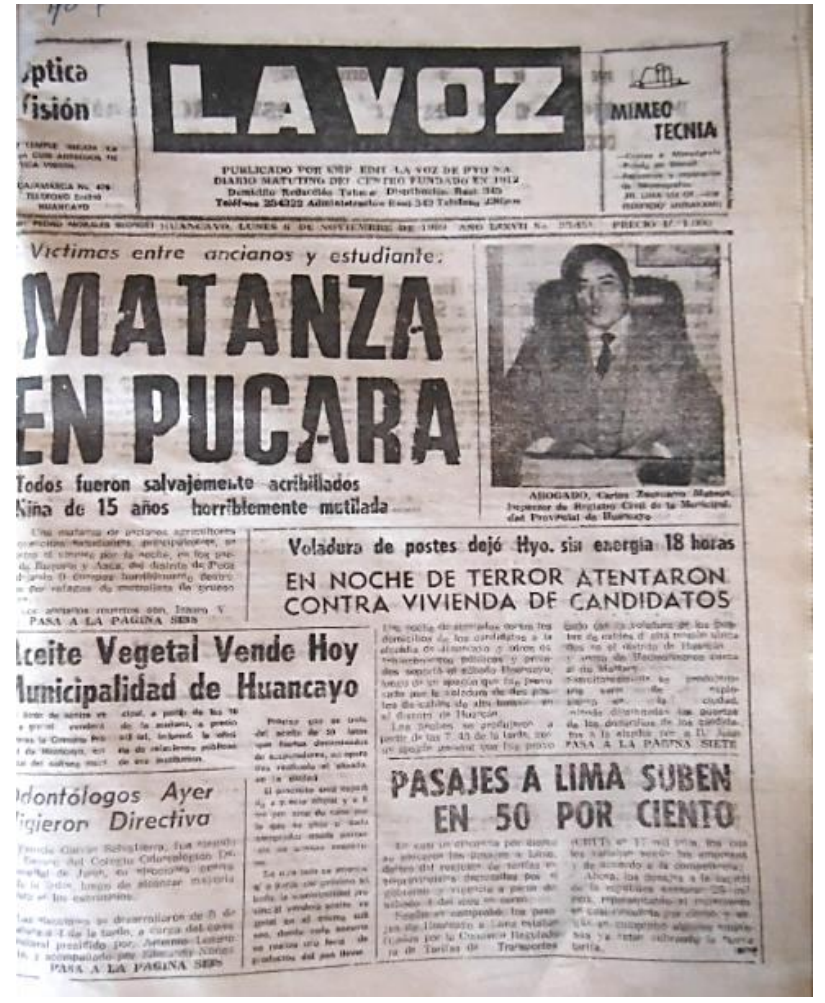

Nota. Tomada de La Voz de Huancayo, 6 de noviembre de 1989.

Esta vez La Voz de Huancayo (Figura 3) cubre uno de los hechos que involucró a soldados del cuartel 9 de diciembre de Huancayo, como lo identificó años después el Informe Final de la CVR. 
A pesar de que el diario envió a un periodista al lugar de los hechos, la información fue construida en base a fuentes oficiales del Estado. En la página interior del 6 de noviembre dice: "Un amanecer sangriento, tiñó de rojo al apacible distrito de Pucará, donde resultaron ocho personas muertas a balazos, producto de una violenta incursión subversiva, (...) informó la Policía Nacional” (La Voz de Huancayo, 1989, p.5). En este fragmento notamos que, a falta de una investigación periodística, se incurrió en un error, pues La Voz de Huancayo sindicó a los "subversivos" como autores de la masacre (se demostró después que fueron los militares), colaborando, nuevamente, con el statu quo ideal de los terroristas: una ciudad tomada por la violencia.

\section{Discusión}

Los tres casos de violencia política presentados y publicados por los diarios Correo y La Voz de Huancayo han tenido como sujetos de la noticia a los principales actores del conflicto armado interno peruano: políticos, fuerzas del orden, comunidades campesinas y el grupo armado Sendero Luminoso. De modo que el tratamiento periodístico que le dieron estos medios a estos sucesos reflejó una realidad parcial. Esta construcción de la realidad elaborada desde la perspectiva del periodista y la institución mediática se caracterizó por presentarnos un escenario desolador, desprotegido y asediado por SL. Esta característica los emparentó con la cobertura de algunos diarios limeños en los primeros años de terrorismo. Debe recordarse que el diario Correo fungía como una filial de la cadena de diarios de la familia Agois Pulsen y desde 1962 conservaba la escuela periodística de los fundadores de Correo de Lima. No obstante, el tratamiento que le dio La Voz de Huancayo se emparentó con menos intensidad al tratamiento de los diarios limeños que explotaban las noticias de terrorismo. Este detalle puede explicarse por carencias logísticas, tecnológicas y económicas del diario. Además, de que La Voz de Huancayo afrontaba una crisis interna, su plana periodística era menor y menos equipada que su competidor Correo. De modo que las noticias sobre terrorismo no profundizaban en los hechos, ni sindicaban directamente a los protagonistas de la guerra que, como se dijo, habían comprometido las libertades de expresión y el derecho a la información en la zona centro. Esto conllevó, por ejemplo, a que el diario en el caso de autoridades con filiaciones políticas o hechos que se presumían eran responsables los militares, diera un tratamiento casi telegráfico de la noticia. Pero al tratarse de víctimas como comuneros de la zona altoandina, La Voz de Huancayo fue un poco más explícita en la narración noticiosa. En tanto, el diario Correo aprovechó su moderna logística y el respaldo del aparato mediático de la cadena a la que pertenecía. Hubo un mayor despliegue periodístico e incluso un mayor radio de alcance. Estas características fueron tomadas en cuenta por SL hasta el punto de imaginar al diario no como una empresa, sino como un rival político. 


\section{Conclusión}

Los diarios en Huancayo condenaron las acciones de Sendero Luminoso, pero mostraron poco interés por comprender y contextualizar las motivaciones ideológicas de este grupo armado. La mayoría de sus informaciones sobre la subversión fue tratada como noticia de crónica roja.

Mientras Correo profundizaba en algún acontecimiento subversivo, La Voz de Huancayo no le daba trascendencia, y viceversa. Así se perdió un importante espacio de debate. Las múltiples razones de esto, como dijimos, estuvieron asociadas a la línea editorial, los intereses económicos, las amenazas a los directivos y el nulo trabajo del periodismo de investigación.

Los periodistas de Correo y La Voz de Huancayo no investigaron en profundidad los tres casos analizados que vinculaban a los grupos terroristas y al ejército peruano, debido a la escasez de garantías y la libertad informativa en la región Junín.

Si bien es cierto que Sendero Luminoso no contó con un aparato mediático, éste supo aprovechar las páginas de los medios escritos de Huancayo para mostrar su letalidad y proyectar en la audiencia el statu quo de una sociedad fragmentada y huérfana de Estado.

Finalmente, la falta de autocrítica y el desconocimiento de la realidad social y política por parte de los periodistas, convirtieron a sus medios de comunicación en cajas de resonancia para la guerra ideológica de Sendero Luminoso.

\section{Referencias}

Arauco, C. (1958). El periodismo en Huancayo. Ediciones Raíz.

Acevedo, J. (2002). Prensa y Violencia Política (1980-1995). Aproximación a las visiones de los Derechos Humanos en el Perú. Asociación de Comunicadores Sociales Calandria.

Comisión de la Verdad y Reconciliación (Región Centro) (2003). 100 Voces y miradas: opiniones sobre verdad, justicia y reconciliación en la Región Centro. Área de Impacto Público y USAID.

Comisión de la Verdad y Reconciliación (2002). Final Report (Audiencias públicas en Huancayo). Comisión de la Verdad y Reconciliación. http://www.cverdad.org.pe/ingles/apublicas/audiencias/trans_huancayo03i.php.

Comisión de la Verdad y Reconciliación (2003a). Informe final (Tomo IV) - Primera Parte - El Proceso, los hechos, las víctimas. Autor.

Comisión de la Verdad y Reconciliación (2003b). Informe final (Tomo VII) - Primera Parte - El Proceso, los hechos, las víctimas. Autor.

Correo (14 de abril de 1989). Más de 15 serían las víctimas. Diario Correo. p.7. 
Correo (21 de abril de 1983). iNo podrán acallarnos!. Diario Correo. p.1.

Cueto, M. (2009). Ayacucho: Prensa y Violencia. DSG Vargas.

Desco Centro de Estudios y Promoción del Desarrollo. (1989). Violencia Política en el Perú (19801988), Tomo II. Desco.

Domenach, J. (1981) La violencia. En Organización de las Naciones Unidas, La Violencia y sus causas, pp. 33-45, Unesco.

Febres, J. (2011). Medios de comunicación, violencia y terrorismo. Editorial Dunken.

Galván, I. (12 de mayo de 2014). iTiracho Wanka abate Picaflor! El Huacón, p.24.

Gargurevich, J. (2005). Mario Vargas LLosa. Reportero a los quince años. Fondo Editorial PUCP.

Gonzales, C. (1992). La prensa como reflejo de desarticulación social. Prensa y violencia en el Perú, el caso de Sendero Luminoso. CICOSUL.

Gorriti, G. (2017). Sendero. Historia de la guerra milenaria en el Perú. Editorial Planeta.

Halloran, J. (1981). Los medios de comunicación social: ¿síntomas o causas de la violencia? En Organización de las Naciones Unidas, La Violencia y sus causas, pp. 139-158, París: Unesco.

Hernández, R., Fernández, C. y Baptista, P. (2006). Metodología de la investigación. McGraw-Hill.

Manrique, N. (1999). La guerra en la región central. IEP -UNSCH.

Nieto, J. (1987). ¿Lobo, estás?. Quehacer, (46), pp. 35-41.

Ñaupas, H., Mejía, E., Novoa E. y Villagómez, A. (2013). Metodología de la investigación científica y elaboración de tesis. Centro de Producción Editorial de la UNMSM.

Osorio, M. y Cisneros, A. (1967). Historia del periodismo en Junín. Huancayo: Visión del Perú.

Oviedo, C. (1989). Prensa y Subversión. Mass Comunicación SRL

Peralta, V. (2000). Sendero Luminoso y la prensa (1980 - 1994): la violencia política peruana y su representación en los medios. CBC.

Quehacer (1987). Los medios y la violencia, (46), pp. 42-45.

Rojas, N. (1974). El Periodismo en el Valle del Mantaro. [tesis de pregrado]. Pontificia Universidad Católica del Perú, Lima.

Rostros que claman justicia. (Setiembre-octubre de 2008). Crónika, (2), pp. 5-9.

Strong, S. (1992). Sendero Luminoso. El movimiento subversivo más letal del mundo. Perú Reporting.

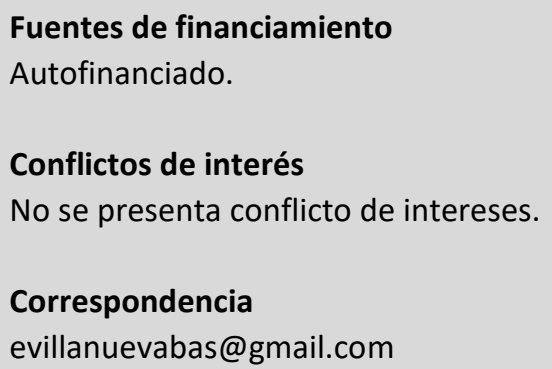

